\title{
The Capital Asset Pricing Model: Theory and Evidence
}

\author{
Eugene F. Fama and Kenneth R. French
}

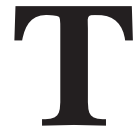

he capital asset pricing model (CAPM) of William Sharpe (1964) and John Lintner (1965) marks the birth of asset pricing theory (resulting in a widely used in applications, such as estimating the cost of capital for firms and evaluating the performance of managed portfolios. It is the centerpiece of MBA investment courses. Indeed, it is often the only asset pricing model taught in these courses. $^{1}$

The attraction of the CAPM is that it offers powerful and intuitively pleasing predictions about how to measure risk and the relation between expected return and risk. Unfortunately, the empirical record of the model is poor-poor enough to invalidate the way it is used in applications. The CAPM's empirical problems may reflect theoretical failings, the result of many simplifying assumptions. But they may also be caused by difficulties in implementing valid tests of the model. For example, the CAPM says that the risk of a stock should be measured relative to a comprehensive "market portfolio" that in principle can include not just traded financial assets, but also consumer durables, real estate and human capital. Even if we take a narrow view of the model and limit its purview to traded financial assets, is it

\footnotetext{
${ }^{1}$ Although every asset pricing model is a capital asset pricing model, the finance profession reserves the acronym CAPM for the specific model of Sharpe (1964), Lintner (1965) and Black (1972) discussed here. Thus, throughout the paper we refer to the Sharpe-Lintner-Black model as the CAPM.
}

Eugene F. Fama is Robert R. McCormick Distinguished Service Professor of Finance, Graduate School of Business, University of Chicago, Chicago, Illinois. Kenneth R. French is Carl E. and Catherine M. Heidt Professor of Finance, Tuck School of Business, Dartmouth College, Hanover, New Hampshire. Their e-mail addresses are 〈eugene.fama@gsb.uchicago. edu〉and〈kfrench@dartmouth.edu〉, respectively. 
legitimate to limit further the market portfolio to U.S. common stocks (a typical choice), or should the market be expanded to include bonds, and other financial assets, perhaps around the world? In the end, we argue that whether the model's problems reflect weaknesses in the theory or in its empirical implementation, the failure of the CAPM in empirical tests implies that most applications of the model are invalid.

We begin by outlining the logic of the CAPM, focusing on its predictions about risk and expected return. We then review the history of empirical work and what it says about shortcomings of the CAPM that pose challenges to be explained by alternative models.

\section{The Logic of the CAPM}

The CAPM builds on the model of portfolio choice developed by Harry Markowitz (1959). In Markowitz's model, an investor selects a portfolio at time $t-1$ that produces a stochastic return at $t$. The model assumes investors are risk averse and, when choosing among portfolios, they care only about the mean and variance of their one-period investment return. As a result, investors choose "meanvariance-efficient" portfolios, in the sense that the portfolios 1) minimize the variance of portfolio return, given expected return, and 2) maximize expected return, given variance. Thus, the Markowitz approach is often called a "meanvariance model."

The portfolio model provides an algebraic condition on asset weights in meanvariance-efficient portfolios. The CAPM turns this algebraic statement into a testable prediction about the relation between risk and expected return by identifying a portfolio that must be efficient if asset prices are to clear the market of all assets.

Sharpe (1964) and Lintner (1965) add two key assumptions to the Markowitz model to identify a portfolio that must be mean-variance-efficient. The first assumption is complete agreement: given market clearing asset prices at $t-1$, investors agree on the joint distribution of asset returns from $t-1$ to $t$. And this distribution is the true one-that is, it is the distribution from which the returns we use to test the model are drawn. The second assumption is that there is borrowing and lending at a risk-free rate, which is the same for all investors and does not depend on the amount borrowed or lent.

Figure 1 describes portfolio opportunities and tells the CAPM story. The horizontal axis shows portfolio risk, measured by the standard deviation of portfolio return; the vertical axis shows expected return. The curve $a b c$, which is called the minimum variance frontier, traces combinations of expected return and risk for portfolios of risky assets that minimize return variance at different levels of expected return. (These portfolios do not include risk-free borrowing and lending.) The tradeoff between risk and expected return for minimum variance portfolios is apparent. For example, an investor who wants a high expected return, perhaps at point $a$, must accept high volatility. At point $T$, the investor can have an interme- 


\section{Figure 1}

\section{Investment Opportunities}

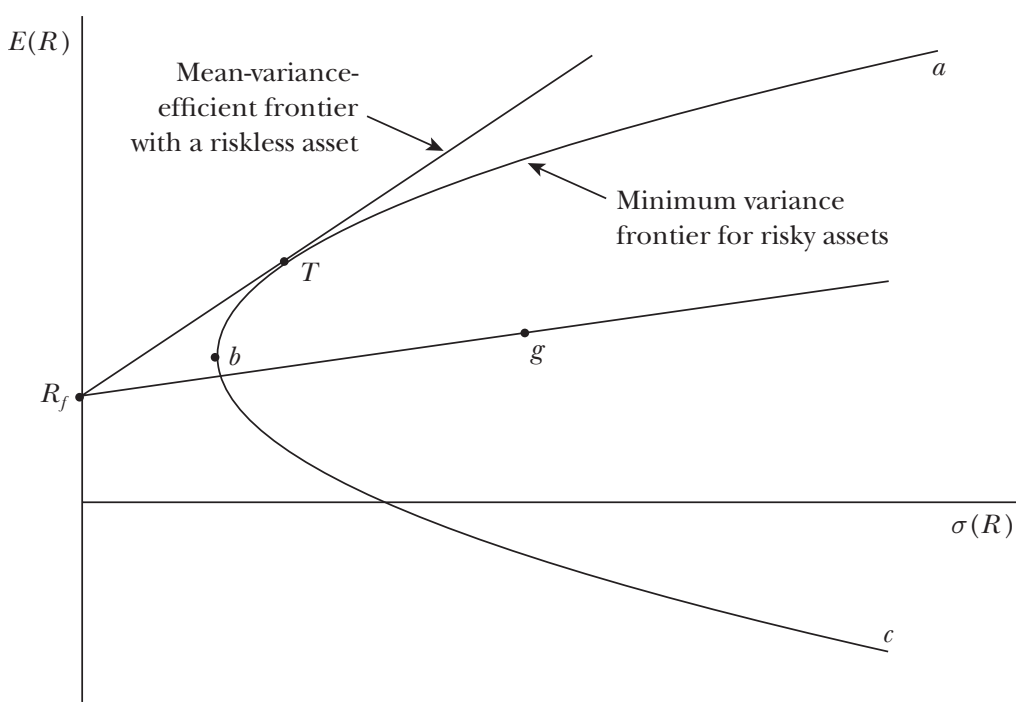

diate expected return with lower volatility. If there is no risk-free borrowing or lending, only portfolios above $b$ along $a b c$ are mean-variance-efficient, since these portfolios also maximize expected return, given their return variances.

Adding risk-free borrowing and lending turns the efficient set into a straight line. Consider a portfolio that invests the proportion $x$ of portfolio funds in a risk-free security and $1-x$ in some portfolio $g$. If all funds are invested in the risk-free security - that is, they are loaned at the risk-free rate of interest-the result is the point $R_{f}$ in Figure 1, a portfolio with zero variance and a risk-free rate of return. Combinations of risk-free lending and positive investment in $g$ plot on the straight line between $R_{f}$ and $g$. Points to the right of $g$ on the line represent borrowing at the risk-free rate, with the proceeds from the borrowing used to increase investment in portfolio $g$. In short, portfolios that combine risk-free lending or borrowing with some risky portfolio $g$ plot along a straight line from $R_{f}$ through $g$ in Figure $1 .^{2}$

${ }^{2}$ Formally, the return, expected return and standard deviation of return on portfolios of the risk-free asset $f$ and a risky portfolio $g$ vary with $x$, the proportion of portfolio funds invested in $f$, as

$$
\begin{gathered}
R_{p}=x R_{f}+(1-x) R_{g}, \\
E\left(R_{p}\right)=x R_{f}+(1-x) E\left(R_{g}\right), \\
\sigma\left(R_{p}\right)=(1-x) \sigma\left(R_{g}\right), x \leq 1.0,
\end{gathered}
$$

which together imply that the portfolios plot along the line from $R_{f}$ through $g$ in Figure 1 . 
To obtain the mean-variance-efficient portfolios available with risk-free borrowing and lending, one swings a line from $R_{f}$ in Figure 1 up and to the left as far as possible, to the tangency portfolio $T$. We can then see that all efficient portfolios are combinations of the risk-free asset (either risk-free borrowing or lending) and a single risky tangency portfolio, T. This key result is Tobin's (1958) "separation theorem."

The punch line of the CAPM is now straightforward. With complete agreement about distributions of returns, all investors see the same opportunity set (Figure 1), and they combine the same risky tangency portfolio $T$ with risk-free lending or borrowing. Since all investors hold the same portfolio $T$ of risky assets, it must be the value-weight market portfolio of risky assets. Specifically, each risky asset's weight in the tangency portfolio, which we now call $M$ (for the "market"), must be the total market value of all outstanding units of the asset divided by the total market value of all risky assets. In addition, the risk-free rate must be set (along with the prices of risky assets) to clear the market for risk-free borrowing and lending.

In short, the CAPM assumptions imply that the market portfolio $M$ must be on the minimum variance frontier if the asset market is to clear. This means that the algebraic relation that holds for any minimum variance portfolio must hold for the market portfolio. Specifically, if there are $N$ risky assets,

(Minimum Variance Condition for $M) \quad E\left(R_{i}\right)=E\left(R_{Z M}\right)$

$$
+\left[E\left(R_{M}\right)-E\left(R_{Z M}\right)\right] \beta_{i M}, i=1, \ldots, N .
$$

In this equation, $E\left(R_{i}\right)$ is the expected return on asset $i$, and $\beta_{i M}$, the market beta of asset $i$, is the covariance of its return with the market return divided by the variance of the market return,

$$
\text { (Market Beta) } \beta_{i M}=\frac{\operatorname{cov}\left(R_{i}, R_{M}\right)}{\sigma^{2}\left(R_{M}\right)} \text {. }
$$

The first term on the right-hand side of the minimum variance condition, $E\left(R_{Z M}\right)$, is the expected return on assets that have market betas equal to zero, which means their returns are uncorrelated with the market return. The second term is a risk premium-the market beta of asset $i, \beta_{i M}$, times the premium per unit of beta, which is the expected market return, $E\left(R_{M}\right)$, minus $E\left(R_{Z M}\right)$.

Since the market beta of asset $i$ is also the slope in the regression of its return on the market return, a common (and correct) interpretation of beta is that it measures the sensitivity of the asset's return to variation in the market return. But there is another interpretation of beta more in line with the spirit of the portfolio model that underlies the CAPM. The risk of the market portfolio, as measured by the variance of its return (the denominator of $\beta_{i M}$ ), is a weighted average of the covariance risks of the assets in $M$ (the numerators of $\beta_{i M}$ for different assets). 
Thus, $\beta_{i M}$ is the covariance risk of asset $i$ in $M$ measured relative to the average covariance risk of assets, which is just the variance of the market return. ${ }^{3}$ In economic terms, $\beta_{i M}$ is proportional to the risk each dollar invested in asset $i$ contributes to the market portfolio.

The last step in the development of the Sharpe-Lintner model is to use the assumption of risk-free borrowing and lending to nail down $E\left(R_{Z M}\right)$, the expected return on zero-beta assets. A risky asset's return is uncorrelated with the market return-its beta is zero-when the average of the asset's covariances with the returns on other assets just offsets the variance of the asset's return. Such a risky asset is riskless in the market portfolio in the sense that it contributes nothing to the variance of the market return.

When there is risk-free borrowing and lending, the expected return on assets that are uncorrelated with the market return, $E\left(R_{Z M}\right)$, must equal the risk-free rate, $R_{f}$. The relation between expected return and beta then becomes the familiar Sharpe-Lintner CAPM equation,

$$
\left(\text { Sharpe-Lintner CAPM) } \quad E\left(R_{i}\right)=R_{f}+\left[E\left(R_{M}\right)-R_{f}\right)\right] \beta_{i M}, i=1, \ldots, N \text {. }
$$

In words, the expected return on any asset $i$ is the risk-free interest rate, $R_{f}$, plus a risk premium, which is the asset's market beta, $\beta_{i M}$, times the premium per unit of beta risk, $E\left(R_{M}\right)-R_{f}$.

Unrestricted risk-free borrowing and lending is an unrealistic assumption. Fischer Black (1972) develops a version of the CAPM without risk-free borrowing or lending. He shows that the CAPM's key result-that the market portfolio is meanvariance-efficient - can be obtained by instead allowing unrestricted short sales of risky assets. In brief, back in Figure 1, if there is no risk-free asset, investors select portfolios from along the mean-variance-efficient frontier from $a$ to $b$. Market clearing prices imply that when one weights the efficient portfolios chosen by investors by their (positive) shares of aggregate invested wealth, the resulting portfolio is the market portfolio. The market portfolio is thus a portfolio of the efficient portfolios chosen by investors. With unrestricted short selling of risky assets, portfolios made up of efficient portfolios are themselves efficient. Thus, the market portfolio is efficient, which means that the minimum variance condition for $M$ given above holds, and it is the expected return-risk relation of the Black CAPM.

The relations between expected return and market beta of the Black and Sharpe-Lintner versions of the CAPM differ only in terms of what each says about $E\left(R_{Z M}\right)$, the expected return on assets uncorrelated with the market. The Black version says only that $E\left(R_{Z M}\right)$ must be less than the expected market return, so the

${ }^{3}$ Formally, if $x_{i M}$ is the weight of asset $i$ in the market portfolio, then the variance of the portfolio's return is

$$
\sigma^{2}\left(R_{M}\right)=\operatorname{Cov}\left(R_{M}, R_{M}\right)=\operatorname{Cov}\left(\sum_{i=1}^{N} x_{i M} R_{i}, R_{M}\right)=\sum_{i=1}^{N} x_{i M} \operatorname{Cov}\left(R_{i}, R_{M}\right)
$$


premium for beta is positive. In contrast, in the Sharpe-Lintner version of the model, $E\left(R_{Z M}\right)$ must be the risk-free interest rate, $R_{f}$, and the premium per unit of beta risk is $E\left(R_{M}\right)-R_{f}$.

The assumption that short selling is unrestricted is as unrealistic as unrestricted risk-free borrowing and lending. If there is no risk-free asset and short sales of risky assets are not allowed, mean-variance investors still choose efficient portfolios-points above $b$ on the $a b c$ curve in Figure 1. But when there is no short selling of risky assets and no risk-free asset, the algebra of portfolio efficiency says that portfolios made up of efficient portfolios are not typically efficient. This means that the market portfolio, which is a portfolio of the efficient portfolios chosen by investors, is not typically efficient. And the CAPM relation between expected return and market beta is lost. This does not rule out predictions about expected return and betas with respect to other efficient portfolios-if theory can specify portfolios that must be efficient if the market is to clear. But so far this has proven impossible.

In short, the familiar CAPM equation relating expected asset returns to their market betas is just an application to the market portfolio of the relation between expected return and portfolio beta that holds in any mean-variance-efficient portfolio. The efficiency of the market portfolio is based on many unrealistic assumptions, including complete agreement and either unrestricted risk-free borrowing and lending or unrestricted short selling of risky assets. But all interesting models involve unrealistic simplifications, which is why they must be tested against data.

\section{Early Empirical Tests}

Tests of the CAPM are based on three implications of the relation between expected return and market beta implied by the model. First, expected returns on all assets are linearly related to their betas, and no other variable has marginal explanatory power. Second, the beta premium is positive, meaning that the expected return on the market portfolio exceeds the expected return on assets whose returns are uncorrelated with the market return. Third, in the Sharpe-Lintner version of the model, assets uncorrelated with the market have expected returns equal to the risk-free interest rate, and the beta premium is the expected market return minus the risk-free rate. Most tests of these predictions use either crosssection or time-series regressions. Both approaches date to early tests of the model.

\section{Tests on Risk Premiums}

The early cross-section regression tests focus on the Sharpe-Lintner model's predictions about the intercept and slope in the relation between expected return and market beta. The approach is to regress a cross-section of average asset returns on estimates of asset betas. The model predicts that the intercept in these regressions is the risk-free interest rate, $R_{f}$, and the coefficient on beta is the expected return on the market in excess of the risk-free rate, $E\left(R_{M}\right)-R_{f}$.

Two problems in these tests quickly became apparent. First, estimates of beta 
for individual assets are imprecise, creating a measurement error problem when they are used to explain average returns. Second, the regression residuals have common sources of variation, such as industry effects in average returns. Positive correlation in the residuals produces downward bias in the usual ordinary least squares estimates of the standard errors of the cross-section regression slopes.

To improve the precision of estimated betas, researchers such as Blume (1970), Friend and Blume (1970) and Black, Jensen and Scholes (1972) work with portfolios, rather than individual securities. Since expected returns and market betas combine in the same way in portfolios, if the CAPM explains security returns it also explains portfolio returns. ${ }^{4}$ Estimates of beta for diversified portfolios are more precise than estimates for individual securities. Thus, using portfolios in cross-section regressions of average returns on betas reduces the critical errors in variables problem. Grouping, however, shrinks the range of betas and reduces statistical power. To mitigate this problem, researchers sort securities on beta when forming portfolios; the first portfolio contains securities with the lowest betas, and so on, up to the last portfolio with the highest beta assets. This sorting procedure is now standard in empirical tests.

Fama and MacBeth (1973) propose a method for addressing the inference problem caused by correlation of the residuals in cross-section regressions. Instead of estimating a single cross-section regression of average monthly returns on betas, they estimate month-by-month cross-section regressions of monthly returns on betas. The times-series means of the monthly slopes and intercepts, along with the standard errors of the means, are then used to test whether the average premium for beta is positive and whether the average return on assets uncorrelated with the market is equal to the average risk-free interest rate. In this approach, the standard errors of the average intercept and slope are determined by the month-to-month variation in the regression coefficients, which fully captures the effects of residual correlation on variation in the regression coefficients, but sidesteps the problem of actually estimating the correlations. The residual correlations are, in effect, captured via repeated sampling of the regression coefficients. This approach also becomes standard in the literature.

Jensen (1968) was the first to note that the Sharpe-Lintner version of the

${ }^{4}$ Formally, if $x_{i p}, i=1, \ldots, N$, are the weights for assets in some portfolio $p$, the expected return and market beta for the portfolio are related to the expected returns and betas of assets as

$$
E\left(R_{p}\right)=\sum_{i=1}^{N} x_{i p} E\left(R_{i}\right), \text { and } \beta_{p M}=\sum_{i=1}^{N} x_{i p} \beta_{p M} .
$$

Thus, the CAPM relation between expected return and beta,

$$
E\left(R_{i}\right)=E\left(R_{f}\right)+\left[E\left(R_{M}\right)-E\left(R_{f}\right)\right] \beta_{i M},
$$

holds when asset $i$ is a portfolio, as well as when $i$ is an individual security. 
relation between expected return and market beta also implies a time-series regression test. The Sharpe-Lintner CAPM says that the expected value of an asset's excess return (the asset's return minus the risk-free interest rate, $R_{i t}-R_{f t}$ ) is completely explained by its expected CAPM risk premium (its beta times the expected value of $R_{M t}-R_{f t}$ ). This implies that "Jensen's alpha," the intercept term in the time-series regression,

$$
\text { (Time-Series Regression) } \quad R_{i t}-R_{f t}=\alpha_{i}+\beta_{i M}\left(R_{M t}-R_{f t}\right)+\varepsilon_{i t},
$$

is zero for each asset.

The early tests firmly reject the Sharpe-Lintner version of the CAPM. There is a positive relation between beta and average return, but it is too "flat." Recall that, in cross-section regressions, the Sharpe-Lintner model predicts that the intercept is the risk-free rate and the coefficient on beta is the expected market return in excess of the risk-free rate, $E\left(R_{M}\right)-R_{f}$. The regressions consistently find that the intercept is greater than the average risk-free rate (typically proxied as the return on a one-month Treasury bill), and the coefficient on beta is less than the average excess market return (proxied as the average return on a portfolio of U.S. common stocks minus the Treasury bill rate). This is true in the early tests, such as Douglas (1968), Black, Jensen and Scholes (1972), Miller and Scholes (1972), Blume and Friend (1973) and Fama and MacBeth (1973), as well as in more recent crosssection regression tests, like Fama and French (1992).

The evidence that the relation between beta and average return is too flat is confirmed in time-series tests, such as Friend and Blume (1970), Black, Jensen and Scholes (1972) and Stambaugh (1982). The intercepts in time-series regressions of excess asset returns on the excess market return are positive for assets with low betas and negative for assets with high betas.

Figure 2 provides an updated example of the evidence. In December of each year, we estimate a preranking beta for every NYSE (1928-2003), AMEX (19632003) and NASDAQ (1972-2003) stock in the CRSP (Center for Research in Security Prices of the University of Chicago) database, using two to five years (as available) of prior monthly returns. ${ }^{5}$ We then form ten value-weight portfolios based on these preranking betas and compute their returns for the next twelve months. We repeat this process for each year from 1928 to 2003. The result is 912 monthly returns on ten beta-sorted portfolios. Figure 2 plots each portfolio's average return against its postranking beta, estimated by regressing its monthly returns for 1928-2003 on the return on the CRSP value-weight portfolio of U.S. common stocks.

The Sharpe-Lintner CAPM predicts that the portfolios plot along a straight

\footnotetext{
${ }^{5}$ To be included in the sample for year $t$, a security must have market equity data (price times shares outstanding) for December of $t-1$, and CRSP must classify it as ordinary common equity. Thus, we exclude securities such as American Depository Receipts (ADRs) and Real Estate Investment Trusts (REITs).
} 
Figure 2

Average Annualized Monthly Return versus Beta for Value Weight Portfolios Formed on Prior Beta, 1928-2003

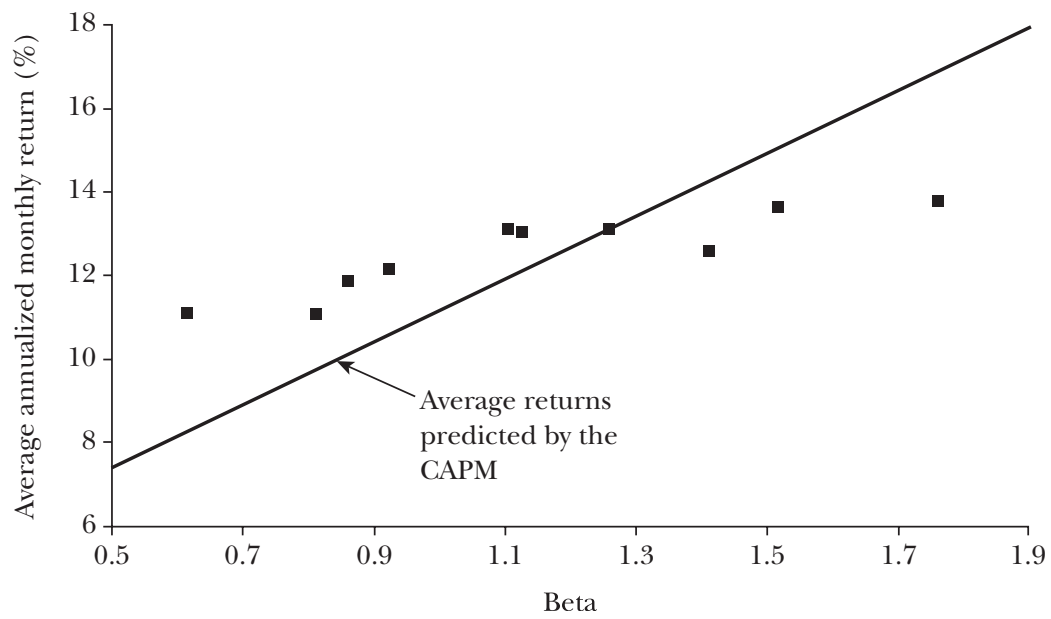

line, with an intercept equal to the risk-free rate, $R_{f}$, and a slope equal to the expected excess return on the market, $E\left(R_{M}\right)-R_{f}$. We use the average one-month Treasury bill rate and the average excess CRSP market return for 1928-2003 to estimate the predicted line in Figure 2. Confirming earlier evidence, the relation between beta and average return for the ten portfolios is much flatter than the Sharpe-Lintner CAPM predicts. The returns on the low beta portfolios are too high, and the returns on the high beta portfolios are too low. For example, the predicted return on the portfolio with the lowest beta is 8.3 percent per year; the actual return is 11.1 percent. The predicted return on the portfolio with the highest beta is 16.8 percent per year; the actual is 13.7 percent.

Although the observed premium per unit of beta is lower than the SharpeLintner model predicts, the relation between average return and beta in Figure 2 is roughly linear. This is consistent with the Black version of the CAPM, which predicts only that the beta premium is positive. Even this less restrictive model, however, eventually succumbs to the data.

\section{Testing Whether Market Betas Explain Expected Returns}

The Sharpe-Lintner and Black versions of the CAPM share the prediction that the market portfolio is mean-variance-efficient. This implies that differences in expected return across securities and portfolios are entirely explained by differences in market beta; other variables should add nothing to the explanation of expected return. This prediction plays a prominent role in tests of the CAPM. In the early work, the weapon of choice is cross-section regressions.

In the framework of Fama and MacBeth (1973), one simply adds predetermined explanatory variables to the month-by-month cross-section regressions of 
returns on beta. If all differences in expected return are explained by beta, the average slopes on the additional variables should not be reliably different from zero. Clearly, the trick in the cross-section regression approach is to choose specific additional variables likely to expose any problems of the CAPM prediction that, because the market portfolio is efficient, market betas suffice to explain expected asset returns.

For example, in Fama and MacBeth (1973) the additional variables are squared market betas (to test the prediction that the relation between expected return and beta is linear) and residual variances from regressions of returns on the market return (to test the prediction that market beta is the only measure of risk needed to explain expected returns). These variables do not add to the explanation of average returns provided by beta. Thus, the results of Fama and MacBeth (1973) are consistent with the hypothesis that their market proxy-an equal-weight portfolio of NYSE stocks-is on the minimum variance frontier.

The hypothesis that market betas completely explain expected returns can also be tested using time-series regressions. In the time-series regression described above (the excess return on asset $i$ regressed on the excess market return), the intercept is the difference between the asset's average excess return and the excess return predicted by the Sharpe-Lintner model, that is, beta times the average excess market return. If the model holds, there is no way to group assets into portfolios whose intercepts are reliably different from zero. For example, the intercepts for a portfolio of stocks with high ratios of earnings to price and a portfolio of stocks with low earning-price ratios should both be zero. Thus, to test the hypothesis that market betas suffice to explain expected returns, one estimates the time-series regression for a set of assets (or portfolios) and then jointly tests the vector of regression intercepts against zero. The trick in this approach is to choose the left-hand-side assets (or portfolios) in a way likely to expose any shortcoming of the CAPM prediction that market betas suffice to explain expected asset returns.

In early applications, researchers use a variety of tests to determine whether the intercepts in a set of time-series regressions are all zero. The tests have the same asymptotic properties, but there is controversy about which has the best small sample properties. Gibbons, Ross and Shanken (1989) settle the debate by providing an $F$-test on the intercepts that has exact small-sample properties. They also show that the test has a simple economic interpretation. In effect, the test constructs a candidate for the tangency portfolio $T$ in Figure 1 by optimally combining the market proxy and the left-hand-side assets of the time-series regressions. The estimator then tests whether the efficient set provided by the combination of this tangency portfolio and the risk-free asset is reliably superior to the one obtained by combining the risk-free asset with the market proxy alone. In other words, the Gibbons, Ross and Shanken statistic tests whether the market proxy is the tangency portfolio in the set of portfolios that can be constructed by combining the market portfolio with the specific assets used as dependent variables in the time-series regressions.

Enlightened by this insight of Gibbons, Ross and Shanken (1989), one can see 
a similar interpretation of the cross-section regression test of whether market betas suffice to explain expected returns. In this case, the test is whether the additional explanatory variables in a cross-section regression identify patterns in the returns on the left-hand-side assets that are not explained by the assets' market betas. This amounts to testing whether the market proxy is on the minimum variance frontier that can be constructed using the market proxy and the left-hand-side assets included in the tests.

An important lesson from this discussion is that time-series and cross-section regressions do not, strictly speaking, test the CAPM. What is literally tested is whether a specific proxy for the market portfolio (typically a portfolio of U.S. common stocks) is efficient in the set of portfolios that can be constructed from it and the left-hand-side assets used in the test. One might conclude from this that the CAPM has never been tested, and prospects for testing it are not good because 1) the set of left-hand-side assets does not include all marketable assets, and 2) data for the true market portfolio of all assets are likely beyond reach (Roll, 1977; more on this later). But this criticism can be leveled at tests of any economic model when the tests are less than exhaustive or when they use proxies for the variables called for by the model.

The bottom line from the early cross-section regression tests of the CAPM, such as Fama and MacBeth (1973), and the early time-series regression tests, like Gibbons (1982) and Stambaugh (1982), is that standard market proxies seem to be on the minimum variance frontier. That is, the central predictions of the Black version of the CAPM, that market betas suffice to explain expected returns and that the risk premium for beta is positive, seem to hold. But the more specific prediction of the Sharpe-Lintner CAPM that the premium per unit of beta is the expected market return minus the risk-free interest rate is consistently rejected.

The success of the Black version of the CAPM in early tests produced a consensus that the model is a good description of expected returns. These early results, coupled with the model's simplicity and intuitive appeal, pushed the CAPM to the forefront of finance.

\section{Recent Tests}

Starting in the late 1970s, empirical work appears that challenges even the Black version of the CAPM. Specifically, evidence mounts that much of the variation in expected return is unrelated to market beta.

The first blow is Basu's (1977) evidence that when common stocks are sorted on earnings-price ratios, future returns on high $\mathrm{E} / \mathrm{P}$ stocks are higher than predicted by the CAPM. Banz (1981) documents a size effect: when stocks are sorted on market capitalization (price times shares outstanding), average returns on small stocks are higher than predicted by the CAPM. Bhandari (1988) finds that high debt-equity ratios (book value of debt over the market value of equity, a measure of leverage) are associated with returns that are too high relative to their market betas. 
Finally, Statman (1980) and Rosenberg, Reid and Lanstein (1985) document that stocks with high book-to-market equity ratios $(\mathrm{B} / \mathrm{M}$, the ratio of the book value of a common stock to its market value) have high average returns that are not captured by their betas.

There is a theme in the contradictions of the CAPM summarized above. Ratios involving stock prices have information about expected returns missed by market betas. On reflection, this is not surprising. A stock's price depends not only on the expected cash flows it will provide, but also on the expected returns that discount expected cash flows back to the present. Thus, in principle, the cross-section of prices has information about the cross-section of expected returns. (A high expected return implies a high discount rate and a low price.) The cross-section of stock prices is, however, arbitrarily affected by differences in scale (or units). But with a judicious choice of scaling variable $X$, the ratio $X / P$ can reveal differences in the cross-section of expected stock returns. Such ratios are thus prime candidates to expose shortcomings of asset pricing models-in the case of the CAPM, shortcomings of the prediction that market betas suffice to explain expected returns (Ball, 1978). The contradictions of the CAPM summarized above suggest that earnings-price, debt-equity and book-to-market ratios indeed play this role.

Fama and French (1992) update and synthesize the evidence on the empirical failures of the CAPM. Using the cross-section regression approach, they confirm that size, earnings-price, debt-equity and book-to-market ratios add to the explanation of expected stock returns provided by market beta. Fama and French (1996) reach the same conclusion using the time-series regression approach applied to portfolios of stocks sorted on price ratios. They also find that different price ratios have much the same information about expected returns. This is not surprising given that price is the common driving force in the price ratios, and the numerators are just scaling variables used to extract the information in price about expected returns.

Fama and French (1992) also confirm the evidence (Reinganum, 1981; Stambaugh, 1982; Lakonishok and Shapiro, 1986) that the relation between average return and beta for common stocks is even flatter after the sample periods used in the early empirical work on the CAPM. The estimate of the beta premium is, however, clouded by statistical uncertainty (a large standard error). Kothari, Shanken and Sloan (1995) try to resuscitate the Sharpe-Lintner CAPM by arguing that the weak relation between average return and beta is just a chance result. But the strong evidence that other variables capture variation in expected return missed by beta makes this argument irrelevant. If betas do not suffice to explain expected returns, the market portfolio is not efficient, and the CAPM is dead in its tracks. Evidence on the size of the market premium can neither save the model nor further doom it.

The synthesis of the evidence on the empirical problems of the CAPM provided by Fama and French (1992) serves as a catalyst, marking the point when it is generally acknowledged that the CAPM has potentially fatal problems. Research then turns to explanations. 
One possibility is that the CAPM's problems are spurious, the result of data dredging-publication-hungry researchers scouring the data and unearthing contradictions that occur in specific samples as a result of chance. A standard response to this concern is to test for similar findings in other samples. Chan, Hamao and Lakonishok (1991) find a strong relation between book-to-market equity (B/M) and average return for Japanese stocks. Capaul, Rowley and Sharpe (1993) observe a similar B/M effect in four European stock markets and in Japan. Fama and French (1998) find that the price ratios that produce problems for the CAPM in U.S. data show up in the same way in the stock returns of twelve non-U.S. major markets, and they are present in emerging market returns. This evidence suggests that the contradictions of the CAPM associated with price ratios are not sample specific.

\section{Explanations: Irrational Pricing or Risk}

Among those who conclude that the empirical failures of the CAPM are fatal, two stories emerge. On one side are the behavioralists. Their view is based on evidence that stocks with high ratios of book value to market price are typically firms that have fallen on bad times, while low B/M is associated with growth firms (Lakonishok, Shleifer and Vishny, 1994; Fama and French, 1995). The behavioralists argue that sorting firms on book-to-market ratios exposes investor overreaction to good and bad times. Investors overextrapolate past performance, resulting in stock prices that are too high for growth (low B/M) firms and too low for distressed (high $\mathrm{B} / \mathrm{M}$, so-called value) firms. When the overreaction is eventually corrected, the result is high returns for value stocks and low returns for growth stocks. Proponents of this view include DeBondt and Thaler (1987), Lakonishok, Shleifer and Vishny (1994) and Haugen (1995).

The second story for explaining the empirical contradictions of the CAPM is that they point to the need for a more complicated asset pricing model. The CAPM is based on many unrealistic assumptions. For example, the assumption that investors care only about the mean and variance of one-period portfolio returns is extreme. It is reasonable that investors also care about how their portfolio return covaries with labor income and future investment opportunities, so a portfolio's return variance misses important dimensions of risk. If so, market beta is not a complete description of an asset's risk, and we should not be surprised to find that differences in expected return are not completely explained by differences in beta. In this view, the search should turn to asset pricing models that do a better job explaining average returns.

Merton's (1973) intertemporal capital asset pricing model (ICAPM) is a natural extension of the CAPM. The ICAPM begins with a different assumption about investor objectives. In the CAPM, investors care only about the wealth their portfolio produces at the end of the current period. In the ICAPM, investors are concerned not only with their end-of-period payoff, but also with the opportunities 
they will have to consume or invest the payoff. Thus, when choosing a portfolio at time $t-1$, ICAPM investors consider how their wealth at $t$ might vary with future state variables, including labor income, the prices of consumption goods and the nature of portfolio opportunities at $t$, and expectations about the labor income, consumption and investment opportunities to be available after $t$.

Like CAPM investors, ICAPM investors prefer high expected return and low return variance. But ICAPM investors are also concerned with the covariances of portfolio returns with state variables. As a result, optimal portfolios are "multifactor efficient," which means they have the largest possible expected returns, given their return variances and the covariances of their returns with the relevant state variables.

Fama (1996) shows that the ICAPM generalizes the logic of the CAPM. That is, if there is risk-free borrowing and lending or if short sales of risky assets are allowed, market clearing prices imply that the market portfolio is multifactor efficient. Moreover, multifactor efficiency implies a relation between expected return and beta risks, but it requires additional betas, along with a market beta, to explain expected returns.

An ideal implementation of the ICAPM would specify the state variables that affect expected returns. Fama and French (1993) take a more indirect approach, perhaps more in the spirit of Ross's (1976) arbitrage pricing theory. They argue that though size and book-to-market equity are not themselves state variables, the higher average returns on small stocks and high book-to-market stocks reflect unidentified state variables that produce undiversifiable risks (covariances) in returns that are not captured by the market return and are priced separately from market betas. In support of this claim, they show that the returns on the stocks of small firms covary more with one another than with returns on the stocks of large firms, and returns on high book-to-market (value) stocks covary more with one another than with returns on low book-to-market (growth) stocks. Fama and French (1995) show that there are similar size and book-to-market patterns in the covariation of fundamentals like earnings and sales.

Based on this evidence, Fama and French $(1993,1996)$ propose a three-factor model for expected returns,

(Three-Factor Model) $\quad E\left(R_{i t}\right)-R_{f t}=\beta_{i M}\left[E\left(R_{M t}\right)-R_{f t}\right]$

$$
+\beta_{i s} E\left(S M B_{t}\right)+\beta_{i h} E\left(H M L_{t}\right) .
$$

In this equation, $S M B_{t}$ (small minus big) is the difference between the returns on diversified portfolios of small and big stocks, $H M L_{t}$ (high minus low) is the difference between the returns on diversified portfolios of high and low $\mathrm{B} / \mathrm{M}$ stocks, and the betas are slopes in the multiple regression of $R_{i t}-R_{f t}$ on $R_{M t}-R_{f t}$, $S M B_{t}$ and $H M L_{t}$.

For perspective, the average value of the market premium $R_{M t}-R_{f t}$ for 1927-2003 is 8.3 percent per year, which is 3.5 standard errors from zero. The 
average values of $S M B_{t}$, and $H M L_{t}$ are 3.6 percent and 5.0 percent per year, and they are 2.1 and 3.1 standard errors from zero. All three premiums are volatile, with annual standard deviations of 21.0 percent $\left(R_{M t}-R_{f t}\right), 14.6$ percent $\left(S M B_{t}\right)$ and 14.2 percent $\left(H M L_{t}\right)$ per year. Although the average values of the premiums are large, high volatility implies substantial uncertainty about the true expected premiums.

One implication of the expected return equation of the three-factor model is that the intercept $\alpha_{\mathrm{i}}$ in the time-series regression,

$$
R_{i t}-R_{f t}=\alpha_{i}+\beta_{i M}\left(R_{M t}-R_{f t}\right)+\beta_{i s} S M B_{t}+\beta_{i h} H M L_{t}+\varepsilon_{i t}
$$

is zero for all assets $i$. Using this criterion, Fama and French $(1993,1996)$ find that the model captures much of the variation in average return for portfolios formed on size, book-to-market equity and other price ratios that cause problems for the CAPM. Fama and French (1998) show that an international version of the model performs better than an international CAPM in describing average returns on portfolios formed on scaled price variables for stocks in 13 major markets.

The three-factor model is now widely used in empirical research that requires a model of expected returns. Estimates of $\alpha_{\mathrm{i}}$ from the time-series regression above are used to calibrate how rapidly stock prices respond to new information (for example, Loughran and Ritter, 1995; Mitchell and Stafford, 2000). They are also used to measure the special information of portfolio managers, for example, in Carhart's (1997) study of mutual fund performance. Among practitioners like Ibbotson Associates, the model is offered as an alternative to the CAPM for estimating the cost of equity capital.

From a theoretical perspective, the main shortcoming of the three-factor model is its empirical motivation. The small-minus-big (SMB) and high-minus-low (HML) explanatory returns are not motivated by predictions about state variables of concern to investors. Instead they are brute force constructs meant to capture the patterns uncovered by previous work on how average stock returns vary with size and the book-to-market equity ratio.

But this concern is not fatal. The ICAPM does not require that the additional portfolios used along with the market portfolio to explain expected returns "mimic" the relevant state variables. In both the ICAPM and the arbitrage pricing theory, it suffices that the additional portfolios are well diversified (in the terminology of Fama, 1996, they are multifactor minimum variance) and that they are sufficiently different from the market portfolio to capture covariation in returns and variation in expected returns missed by the market portfolio. Thus, adding diversified portfolios that capture covariation in returns and variation in average returns left unexplained by the market is in the spirit of both the ICAPM and the Ross's arbitrage pricing theory.

The behavioralists are not impressed by the evidence for a risk-based explanation of the failures of the CAPM. They typically concede that the three-factor model captures covariation in returns missed by the market return and that it picks 
up much of the size and value effects in average returns left unexplained by the CAPM. But their view is that the average return premium associated with the model's book-to-market factor-which does the heavy lifting in the improvements to the CAPM-is itself the result of investor overreaction that happens to be correlated across firms in a way that just looks like a risk story. In short, in the behavioral view, the market tries to set CAPM prices, and violations of the CAPM are due to mispricing.

The conflict between the behavioral irrational pricing story and the rational risk story for the empirical failures of the CAPM leaves us at a timeworn impasse. Fama (1970) emphasizes that the hypothesis that prices properly reflect available information must be tested in the context of a model of expected returns, like the CAPM. Intuitively, to test whether prices are rational, one must take a stand on what the market is trying to do in setting prices-that is, what is risk and what is the relation between expected return and risk? When tests reject the CAPM, one cannot say whether the problem is its assumption that prices are rational (the behavioral view) or violations of other assumptions that are also necessary to produce the CAPM (our position).

Fortunately, for some applications, the way one uses the three-factor model does not depend on one's view about whether its average return premiums are the rational result of underlying state variable risks, the result of irrational investor behavior or sample specific results of chance. For example, when measuring the response of stock prices to new information or when evaluating the performance of managed portfolios, one wants to account for known patterns in returns and average returns for the period examined, whatever their source. Similarly, when estimating the cost of equity capital, one might be unconcerned with whether expected return premiums are rational or irrational since they are in either case part of the opportunity cost of equity capital (Stein, 1996). But the cost of capital is forward looking, so if the premiums are sample specific they are irrelevant.

The three-factor model is hardly a panacea. Its most serious problem is the momentum effect of Jegadeesh and Titman (1993). Stocks that do well relative to the market over the last three to twelve months tend to continue to do well for the next few months, and stocks that do poorly continue to do poorly. This momentum effect is distinct from the value effect captured by book-to-market equity and other price ratios. Moreover, the momentum effect is left unexplained by the three-factor model, as well as by the CAPM. Following Carhart (1997), one response is to add a momentum factor (the difference between the returns on diversified portfolios of short-term winners and losers) to the three-factor model. This step is again legitimate in applications where the goal is to abstract from known patterns in average returns to uncover information-specific or manager-specific effects. But since the momentum effect is short-lived, it is largely irrelevant for estimates of the cost of equity capital.

Another strand of research points to problems in both the three-factor model and the CAPM. Frankel and Lee (1998), Dechow, Hutton and Sloan (1999), Piotroski (2000) and others show that in portfolios formed on price ratios like 
book-to-market equity, stocks with higher expected cash flows have higher average returns that are not captured by the three-factor model or the CAPM. The authors interpret their results as evidence that stock prices are irrational, in the sense that they do not reflect available information about expected profitability.

In truth, however, one can't tell whether the problem is bad pricing or a bad asset pricing model. A stock's price can always be expressed as the present value of expected future cash flows discounted at the expected return on the stock (Campbell and Shiller, 1989; Vuolteenaho, 2002). It follows that if two stocks have the same price, the one with higher expected cash flows must have a higher expected return. This holds true whether pricing is rational or irrational. Thus, when one observes a positive relation between expected cash flows and expected returns that is left unexplained by the CAPM or the three-factor model, one can't tell whether it is the result of irrational pricing or a misspecified asset pricing model.

\section{The Market Proxy Problem}

Roll (1977) argues that the CAPM has never been tested and probably never will be. The problem is that the market portfolio at the heart of the model is theoretically and empirically elusive. It is not theoretically clear which assets (for example, human capital) can legitimately be excluded from the market portfolio, and data availability substantially limits the assets that are included. As a result, tests of the CAPM are forced to use proxies for the market portfolio, in effect testing whether the proxies are on the minimum variance frontier. Roll argues that because the tests use proxies, not the true market portfolio, we learn nothing about the CAPM.

We are more pragmatic. The relation between expected return and market beta of the CAPM is just the minimum variance condition that holds in any efficient portfolio, applied to the market portfolio. Thus, if we can find a market proxy that is on the minimum variance frontier, it can be used to describe differences in expected returns, and we would be happy to use it for this purpose. The strong rejections of the CAPM described above, however, say that researchers have not uncovered a reasonable market proxy that is close to the minimum variance frontier. If researchers are constrained to reasonable proxies, we doubt they ever will.

Our pessimism is fueled by several empirical results. Stambaugh (1982) tests the CAPM using a range of market portfolios that include, in addition to U.S. common stocks, corporate and government bonds, preferred stocks, real estate and other consumer durables. He finds that tests of the CAPM are not sensitive to expanding the market proxy beyond common stocks, basically because the volatility of expanded market returns is dominated by the volatility of stock returns.

One need not be convinced by Stambaugh's (1982) results since his market proxies are limited to U.S. assets. If international capital markets are open and asset prices conform to an international version of the CAPM, the market portfolio 
should include international assets. Fama and French (1998) find, however, that betas for a global stock market portfolio cannot explain the high average returns observed around the world on stocks with high book-to-market or high earningsprice ratios.

A major problem for the CAPM is that portfolios formed by sorting stocks on price ratios produce a wide range of average returns, but the average returns are not positively related to market betas (Lakonishok, Shleifer and Vishny, 1994; Fama and French, 1996, 1998). The problem is illustrated in Figure 3, which shows average returns and betas (calculated with respect to the CRSP value-weight portfolio of NYSE, AMEX and NASDAQ stocks) for July 1963 to December 2003 for ten portfolios of U.S. stocks formed annually on sorted values of the book-to-market equity ratio $(\mathrm{B} / \mathrm{M}){ }^{6}$

Average returns on the $\mathrm{B} / \mathrm{M}$ portfolios increase almost monotonically, from 10.1 percent per year for the lowest $\mathrm{B} / \mathrm{M}$ group (portfolio 1) to an impressive 16.7 percent for the highest (portfolio 10). But the positive relation between beta and average return predicted by the CAPM is notably absent. For example, the portfolio with the lowest book-to-market ratio has the highest beta but the lowest average return. The estimated beta for the portfolio with the highest book-tomarket ratio and the highest average return is only 0.98 . With an average annualized value of the riskfree interest rate, $R_{f}$, of 5.8 percent and an average annualized market premium, $R_{M}-R_{f}$, of 11.3 percent, the Sharpe-Lintner CAPM predicts an average return of 11.8 percent for the lowest $\mathrm{B} / \mathrm{M}$ portfolio and 11.2 percent for the highest, far from the observed values, 10.1 and 16.7 percent. For the SharpeLintner model to "work" on these portfolios, their market betas must change dramatically, from 1.09 to 0.78 for the lowest B/M portfolio and from 0.98 to 1.98 for the highest. We judge it unlikely that alternative proxies for the market portfolio will produce betas and a market premium that can explain the average returns on these portfolios.

It is always possible that researchers will redeem the CAPM by finding a reasonable proxy for the market portfolio that is on the minimum variance frontier. We emphasize, however, that this possibility cannot be used to justify the way the CAPM is currently applied. The problem is that applications typically use the same

\footnotetext{
${ }^{6}$ Stock return data are from CRSP, and book equity data are from Compustat and the Moody's Industrials, Transportation, Utilities and Financials manuals. Stocks are allocated to ten portfolios at the end of June of each year $t$ (1963 to 2003) using the ratio of book equity for the fiscal year ending in calendar year $t-1$, divided by market equity at the end of December of $t-1$. Book equity is the book value of stockholders' equity, plus balance sheet deferred taxes and investment tax credit (if available), minus the book value of preferred stock. Depending on availability, we use the redemption, liquidation or par value (in that order) to estimate the book value of preferred stock. Stockholders' equity is the value reported by Moody's or Compustat, if it is available. If not, we measure stockholders' equity as the book value of common equity plus the par value of preferred stock or the book value of assets minus total liabilities (in that order). The portfolios for year $t$ include NYSE (1963-2003), AMEX (1963-2003) and NASDAQ (1972-2003) stocks with positive book equity in $t-1$ and market equity (from CRSP) for December of $t-1$ and June of $t$. The portfolios exclude securities CRSP does not classify as ordinary common equity. The breakpoints for year $t$ use only securities that are on the NYSE in June of year $t$.
} 


\section{Figure 3}

\section{Average Annualized Monthly Return versus Beta for Value Weight Portfolios Formed on B/M, 1963-2003}

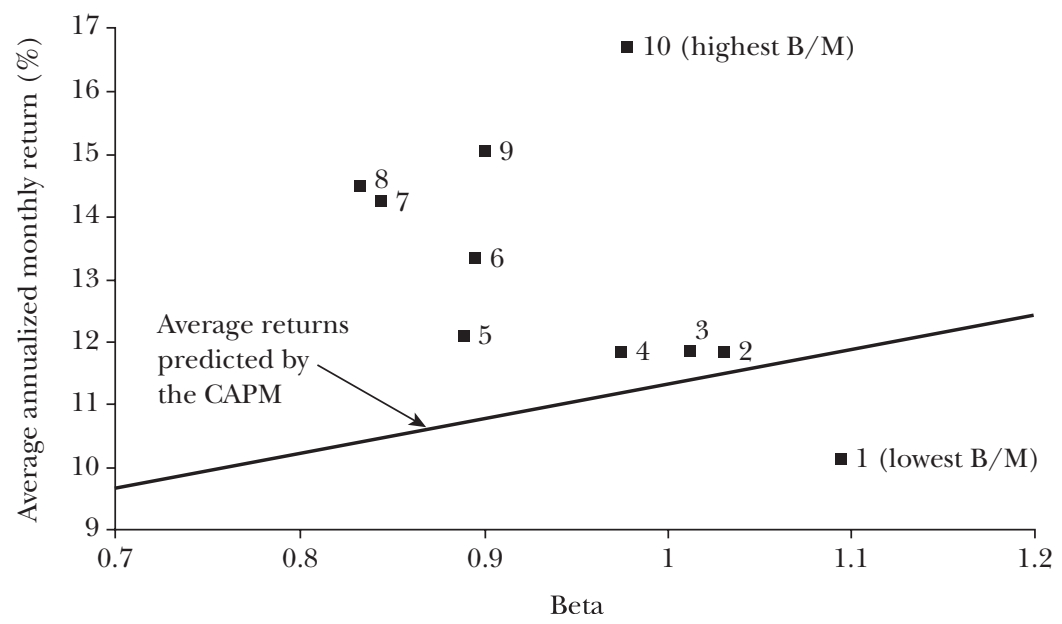

market proxies, like the value-weight portfolio of U.S. stocks, that lead to rejections of the model in empirical tests. The contradictions of the CAPM observed when such proxies are used in tests of the model show up as bad estimates of expected returns in applications; for example, estimates of the cost of equity capital that are too low (relative to historical average returns) for small stocks and for stocks with high book-to-market equity ratios. In short, if a market proxy does not work in tests of the CAPM, it does not work in applications.

\section{Conclusions}

The version of the CAPM developed by Sharpe (1964) and Lintner (1965) has never been an empirical success. In the early empirical work, the Black (1972) version of the model, which can accommodate a flatter tradeoff of average return for market beta, has some success. But in the late 1970s, research begins to uncover variables like size, various price ratios and momentum that add to the explanation of average returns provided by beta. The problems are serious enough to invalidate most applications of the CAPM.

For example, finance textbooks often recommend using the Sharpe-Lintner CAPM risk-return relation to estimate the cost of equity capital. The prescription is to estimate a stock's market beta and combine it with the risk-free interest rate and the average market risk premium to produce an estimate of the cost of equity. The typical market portfolio in these exercises includes just U.S. common stocks. But empirical work, old and new, tells us that the relation between beta and average return is flatter than predicted by the Sharpe-Lintner version of the CAPM. As a 
result, CAPM estimates of the cost of equity for high beta stocks are too high (relative to historical average returns) and estimates for low beta stocks are too low (Friend and Blume, 1970). Similarly, if the high average returns on value stocks (with high book-to-market ratios) imply high expected returns, CAPM cost of equity estimates for such stocks are too low. ${ }^{7}$

The CAPM is also often used to measure the performance of mutual funds and other managed portfolios. The approach, dating to Jensen (1968), is to estimate the CAPM time-series regression for a portfolio and use the intercept (Jensen's alpha) to measure abnormal performance. The problem is that, because of the empirical failings of the CAPM, even passively managed stock portfolios produce abnormal returns if their investment strategies involve tilts toward CAPM problems (Elton, Gruber, Das and Hlavka, 1993). For example, funds that concentrate on low beta stocks, small stocks or value stocks will tend to produce positive abnormal returns relative to the predictions of the Sharpe-Lintner CAPM, even when the fund managers have no special talent for picking winners.

The CAPM, like Markowitz's $(1952,1959)$ portfolio model on which it is built, is nevertheless a theoretical tour de force. We continue to teach the CAPM as an introduction to the fundamental concepts of portfolio theory and asset pricing, to be built on by more complicated models like Merton's (1973) ICAPM. But we also warn students that despite its seductive simplicity, the CAPM's empirical problems probably invalidate its use in applications.

- We gratefully acknowledge the comments of John Cochrane, George Constantinides, Richard Leftwich, Andrei Shleifer, René Stulz and Timothy Taylor.

\footnotetext{
${ }^{7}$ The problems are compounded by the large standard errors of estimates of the market premium and of betas for individual stocks, which probably suffice to make CAPM estimates of the cost of equity rather meaningless, even if the CAPM holds (Fama and French, 1997; Pastor and Stambaugh, 1999). For example, using the U.S. Treasury bill rate as the risk-free interest rate and the CRSP value-weight portfolio of publicly traded U.S. common stocks, the average value of the equity premium $R_{M t}-R_{f t}$ for 1927-2003 is 8.3 percent per year, with a standard error of 2.4 percent. The two standard error range thus runs from 3.5 percent to 13.1 percent, which is sufficient to make most projects appear either profitable or unprofitable. This problem is, however, hardly special to the CAPM. For example, expected returns in all versions of Merton's (1973) ICAPM include a market beta and the expected market premium. Also, as noted earlier the expected values of the size and book-to-market premiums in the Fama-French three-factor model are also estimated with substantial error.
} 


\section{References}

Ball, Ray. 1978. "Anomalies in Relationships Between Securities' Yields and Yield-Surrogates." Journal of Financial Economics. 6:2, pp. 103-26.

Banz, Rolf W. 1981. "The Relationship Between Return and Market Value of Common Stocks." Journal of Financial Economics. 9:1, pp. 3-18.

Basu, Sanjay. 1977. "Investment Performance of Common Stocks in Relation to Their PriceEarnings Ratios: A Test of the Efficient Market Hypothesis." Journal of Finance. 12:3, pp. 129-56.

Bhandari, Laxmi Chand. 1988. "Debt/Equity Ratio and Expected Common Stock Returns: Empirical Evidence." Journal of Finance. 43:2, pp. 507-28.

Black, Fischer. 1972. "Capital Market Equilibrium with Restricted Borrowing." Journal of Business. 45:3, pp. 444-54.

Black, Fischer, Michael C. Jensen and Myron Scholes. 1972. "The Capital Asset Pricing Model: Some Empirical Tests," in Studies in the Theory of Capital Markets. Michael C. Jensen, ed. New York: Praeger, pp. 79-121.

Blume, Marshall. 1970. "Portfolio Theory: A Step Towards its Practical Application." Journal of Business. 43:2, pp. 152-74.

Blume, Marshall and Irwin Friend. 1973. "A New Look at the Capital Asset Pricing Model." Journal of Finance. 28:1, pp. 19-33.

Campbell, John Y. and Robert J. Shiller. 1989. "The Dividend-Price Ratio and Expectations of Future Dividends and Discount Factors." Review of Financial Studies. 1:3, pp. 195-228.

Capaul, Carlo, Ian Rowley and William F. Sharpe. 1993. "International Value and Growth Stock Returns." Financial Analysts Journal. January/February, 49, pp. 27-36.

Carhart, Mark M. 1997. "On Persistence in Mutual Fund Performance." Journal of Finance. 52:1, pp. 57-82.

Chan, Louis K.C., Yasushi Hamao and Josef Lakonishok. 1991. "Fundamentals and Stock Returns in Japan.” Journal of Finance. 46:5, pp. 1739-789.

DeBondt, Werner F. M. and Richard H. Thaler. 1987. "Further Evidence on Investor Overreaction and Stock Market Seasonality." Journal of Finance. 42:3, pp. 557-81.

Dechow, Patricia M., Amy P. Hutton and Richard G. Sloan. 1999. "An Empirical Assessment of the Residual Income Valuation Model." Journal of Accounting and Economics. 26:1, pp. 1-34.

Douglas, George W. 1968. Risk in the Equity Markets: An Empirical Appraisal of Market Efficiency.
Ann Arbor, Michigan: University Microfilms, Inc.

Elton, Edwin J., Martin J. Gruber, Sanjiv Das and Matt Hlavka. 1993. "Efficiency with Costly Information: A Reinterpretation of Evidence from Managed Portfolios." Review of Financial Studies. 6:1, pp. 1-22.

Fama, Eugene F. 1970. "Efficient Capital Markets: A Review of Theory and Empirical Work." Journal of Finance. 25:2, pp. 383-417.

Fama, Eugene F. 1996. "Multifactor Portfolio Efficiency and Multifactor Asset Pricing." Journal of Financial and Quantitative Analysis. 31:4, pp. 441-65.

Fama, Eugene F. and Kenneth R. French. 1992. "The Cross-Section of Expected Stock Returns." Journal of Finance. 47:2, pp. 427-65.

Fama, Eugene F. and Kenneth R. French. 1993. "Common Risk Factors in the Returns on Stocks and Bonds." Journal of Financial Economics. 33:1, pp. 3-56.

Fama, Eugene F. and Kenneth R. French. 1995. "Size and Book-to-Market Factors in Earnings and Returns." Journal of Finance. 50:1, pp. 131-55.

Fama, Eugene F. and Kenneth R. French. 1996. "Multifactor Explanations of Asset Pricing Anomalies." Journal of Finance. 51:1, pp. 55-84.

Fama, Eugene F. and Kenneth R. French. 1997. "Industry Costs of Equity." Journal of Financial Economics. 43:2 pp. 153-93.

Fama, Eugene F. and Kenneth R. French. 1998. "Value Versus Growth: The International Evidence." Journal of Finance. 53:6, pp. 1975-999.

Fama, Eugene F. and James D. MacBeth. 1973. "Risk, Return, and Equilibrium: Empirical Tests." Journal of Political Economy. 81:3, pp. $607-36$.

Frankel, Richard and Charles M.C. Lee. 1998. "Accounting Valuation, Market Expectation, and Cross-Sectional Stock Returns." Journal of Accounting and Economics. 25:3 pp. 283-319.

Friend, Irwin and Marshall Blume. 1970. "Measurement of Portfolio Performance under Uncertainty." American Economic Review. 60:4, pp. 607-36.

Gibbons, Michael R. 1982. "Multivariate Tests of Financial Models: A New Approach.” Journal of Financial Economics. 10:1, pp. 3-27.

Gibbons, Michael R., Stephen A. Ross and Jay Shanken. 1989. "A Test of the Efficiency of a Given Portfolio.” Econometrica. 57:5, pp. 1121152.

Haugen, Robert. 1995. The New Finance: The 
Case against Efficient Markets. Englewood Cliffs, N.J.: Prentice Hall.

Jegadeesh, Narasimhan and Sheridan Titman. 1993. "Returns to Buying Winners and Selling Losers: Implications for Stock Market Efficiency." Journal of Finance. 48:1, pp. 65-91.

Jensen, Michael C. 1968. "The Performance of Mutual Funds in the Period 1945-1964." Journal of Finance. 23:2, pp. 389-416.

Kothari, S. P., Jay Shanken and Richard G. Sloan. 1995. "Another Look at the Cross-Section of Expected Stock Returns." Journal of Finance. 50:1, pp. 185-224.

Lakonishok, Josef and Alan C. Shapiro. 1986. Systemaitc Risk, Total Risk, and Size as Determinants of Stock Market Returns." Journal of Banking and Finance. 10:1, pp. 115-32.

Lakonishok, Josef, Andrei Shleifer and Robert W. Vishny. 1994. "Contrarian Investment, Extrapolation, and Risk." Journal of Finance. 49:5, pp. 1541-578.

Lintner, John. 1965. "The Valuation of Risk Assets and the Selection of Risky Investments in Stock Portfolios and Capital Budgets." Review of Economics and Statistics. 47:1, pp. 13-37.

Loughran, Tim and Jay. R. Ritter. 1995. "The New Issues Puzzle." Journal of Finance. 50:1, pp. 23-51.

Markowitz, Harry. 1952. "Portfolio Selection." Journal of Finance. 7:1, pp. 77-99.

Markowitz, Harry. 1959. Portfolio Selection: Efficient Diversification of Investments. Cowles Foundation Monograph No. 16. New York: John Wiley \& Sons, Inc.

Merton, Robert C. 1973. "An Intertemporal Capital Asset Pricing Model.” Econometrica. 41:5, pp. 867-87.

Miller, Merton and Myron Scholes. 1972. "Rates of Return in Relation to Risk: A Reexamination of Some Recent Findings," in Studies in the Theory of Capital Markets. Michael C. Jensen, ed. New York: Praeger, pp. 47-78.

Mitchell, Mark L. and Erik Stafford. 2000. "Managerial Decisions and Long-Term Stock
Price Performance." Journal of Business. 73:3, pp. 287-329.

Pastor, Lubos and Robert F. Stambaugh. 1999. "Costs of Equity Capital and Model Mispricing." Journal of Finance. 54:1, pp. 67-121.

Piotroski, Joseph D. 2000. "Value Investing: The Use of Historical Financial Statement Information to Separate Winners from Losers." Journal of Accounting Research. 38:Supplement, pp. 1-51.

Reinganum, Marc R. 1981. "A New Empirical Perspective on the CAPM." Journal of Financial and Quantitative Analysis. 16:4, pp. 439-62.

Roll, Richard. 1977. "A Critique of the Asset Pricing Theory's Tests' Part I: On Past and Potential Testability of the Theory." Journal of Financial Economics. 4:2, pp. 129-76.

Rosenberg, Barr, Kenneth Reid and Ronald Lanstein. 1985. "Persuasive Evidence of Market Inefficiency." Journal of Portfolio Management. Spring, 11, pp. 9-17.

Ross, Stephen A. 1976. "The Arbitrage Theory of Capital Asset Pricing." Journal of Economic Theory. 13:3, pp. 341-60.

Sharpe, William F. 1964. "Capital Asset Prices: A Theory of Market Equilibrium under Conditions of Risk." Journal of Finance. 19:3, pp. 42542.

Stambaugh, Robert F. 1982. "On The Exclusion of Assets from Tests of the Two-Parameter Model: A Sensitivity Analysis." Journal of Financial Economics. 10:3, pp. 237-68.

Stattman, Dennis. 1980. "Book Values and Stock Returns." The Chicago MBA: A Journal of Selected Papers. 4, pp. 25-45.

Stein, Jeremy. 1996. "Rational Capital Budgeting in an Irrational World." Journal of Business. 69:4, pp. 429-55.

Tobin, James. 1958. "Liquidity Preference as Behavior Toward Risk." Review of Economic Studies. 25:2, pp. 65-86.

Vuolteenaho, Tuomo. 2002. "What Drives Firm Level Stock Returns?" Journal of Finance. 57:1, pp. 233-64. 